\title{
Paediatric clinician's experiences of parental online health information seeking: a qualitative study
}

Type of manuscript: Original Article

Authors: Lily Shervington ${ }^{1}$, Dr Neil Wimalasundera ${ }^{2}$, Professor Clare Delany ${ }^{1}$

Institution: The Royal Children’s Hospital Melbourne

50 Flemington Rd, Parkville VIC 3052

Correspondence to: Lily Shervington ${ }^{1}$

2/30 Napoleon St., Collingwood, VIC 3066

Lilyshervington93@gmail.com

(61)434980936

${ }^{1}$ The Department of Paediatrics, University of Melbourne, Australia

${ }^{2}$ Royal Children’s Hospital, Melbourne, Australia

\section{Acknowledgements}

The authors would like to thank the participants of the project for giving up their time to contribute their experiences and expertise.

\section{Conflicts of interest}

None declared

This is the author manuscript accepted for publication and has undergone full peer review but has not been through the copyediting, typesetting, pagination and proofreading process, which may lead to differences between this version and the Version of Record. Please cite this article as doi: $10.1111 /$ jpc.14706

This article is protected by copyright. All rights reserved. 


\section{Contributors}

All three authors contributed to the design, analysis and writing in this paper. LS collected the data and all three authors contributed to the analysis and writing.

\section{Funding}

This research received no specific grant from any funding agency in the public, commercial or not-forprofit sectors

\section{ABSTRACT}

\section{Aims:}

The aim of this research was to explore clinicians' experiences of parents' online health information seeking behaviour about selective dorsal rhizotomy for the management of cerebral palsy.

\section{Methods:}

Using qualitative methodology, clinicians likely to have had experience with parents requesting selective dorsal rhizotomy were invited to participate in semi-structured interviews. Interviews with 13 clinicians were recorded, transcribed, and inductive content analysis was used to identify, code and organise the data into themes.

\section{Results:}

Participants highlighted how parental online health information seeking was changing clinical communication. Negative effects included a shift in clinicians' attention from giving advice and guidance to spending time discussing online findings, justifying how this information applies to a particular child and managing parents' judgments about clinical views. Positive effects included more collaboration and sharing of ideas. These results are presented in three main themes: 1)The informed parent; 2)The clinicians’ role; and 3)A new clinical dynamic.

\section{Conclusion:}

This research reinforces the notion that online health information seeking is changing the communication dynamic and clinicians' and parents' roles within the clinical encounter. Of significance was the number of challenges clinicians are facing as a result of online information, including managing parental 
understanding of non-evidenced information and responding to negative feedback about their practice. This research suggests a need for educational support and ongoing professional development for clinicians to assist them to adjust to new goals and expectations of clinical interactions with 'informed' parents.

Key words: Information Seeking Behavior, Online, Internet, Rhizotomy, Cerebral Palsy, Paediatrics 
What is already known on this topic?

- There is substantial growth of e-health, social media and networking sites for child conditions.

- Increasing numbers of parents are seeking health information online on behalf of their child.

- Positive effects of OHIS include more 'informed' and 'empowered' parents and negative effects include harm from misleading information.

\section{What this paper adds?}

- $\quad$ OHIS is changing the role of the parent, the clinician and the overall dynamic of the clinical encounter.

- Clinicians are uncertain and, at times, struggling to adjust to this new clinical dynamic.

- This study suggests there is a need for some form of education or support for clinicians to aid them in adjusting to the 'informed' parent.

This article is protected by copyright. All rights reserved. 


\section{INTRODUCTION}

'Online health information seeking'(OHIS) refers to "internet users who search online for information on health topics, whether they are acting as consumers, caregivers or patients”1p1 aiming to take more control of their health. In the paediatric health setting, the growth of e-health, social media and networking sites has resulted in increasing numbers of parents seeking health information online on behalf of their child ${ }^{2,3}$, and there is a growing literature examining this phenomenon. Reported positive effects of OHIS include the emergence of more 'informed' parents ${ }^{4-6}$, more balance in the clinician-parent relationship ${ }^{7}$, more collaborative consults ${ }^{5,8}$ and opportunities for greater parental support ${ }^{5,9,10}$. Negative effects include proliferation of misleading information ${ }^{11-13}$, increased possibility for conflict between clinicians and parents $^{12,14}$ and less 'efficient' clinical encounters due to discussing online information ${ }^{7,15}$. A notable feature of existing research is that it predominantly focuses on experiences and effects of OHIS on parents. There is proportionately less research examining clinicians’ OHIS experiences and responses.

In this paper, we focus on clinicians' perspectives of parents OHIS for the management of a specific paediatric condition: cerebral palsy (CP) using selective dorsal rhizotomy (SDR). SDR is a neurosurgical procedure which reduces spasticity and aims to improve mobility in selected children with spastic $\mathrm{CP}^{16}$. Four specific factors about SDR make it a particularly good example to examine clinicians' responses to parental OHIS. First, there are no absolute guidelines for its clinical indication. This means clinicians cannot be definitive about success or candidate suitability ${ }^{16}$. Second, CP is a lifelong condition affecting a child's functional capacity in different ways as they grow ${ }^{17}$. Parents, therefore, are constantly searching for ways to improve their child's situation. Third, a centre in the United States which has a strong online presence uses a wider selection criteria for SDR and tends to predict more positive outcomes than mainstream evidence ${ }^{18}$. Fourth, a community of parents who have accessed this treatment have created a bias of positive outcomes online ${ }^{2}$. These factors combine to make SDR an ideal habitat for OHIS behaviours to flourish.

To examine clinicians' perspectives of parental OHIS about SDR for CP, a qualitative approach was used. This involved semi-structured interviews with clinicians involved in the care of children with CP to explore their experiences and how they are responding to online health information (OHI) brought by parents into clinical encounters. 


\section{METHODOLOGY AND METHODS}

The Standards for Reporting Qualitative Research (SRQR) reporting guidelines were utilised for this research $^{19}$.

\section{- Qualitative approach}

The goals of this research were to understand the experiences and the meaning clinicians give to the phenomenon of parents requesting specific treatment for their child based on online health information. The research design therefore draws from qualitative methodologies of phenomenology and interpretivism to frame and guide this enquiry ${ }^{20-22}$. To understand clinicians' experiences, data was collected using semi-structured interviews ${ }^{20-22}$.

\section{- Role of the researcher}

This research was conducted by LS in fulfilment of her University of Melbourne Medical Research Project(MDRP). LS had no prior relationship with any of the participants. As the participants were colleagues of NW, his access was limited to analysed data.

\section{- Participant selection and recruitment}

Purposive sampling was used to recruit clinicians involved in the care of children with CP and experience with parental OHIS. Participants were recruited using the contacts of NW, who, in accordance with ethics protocol, passed on email addresses to LS.

\section{- Data collection}

Participants chose the location and time of the interview. 11 of the interviews were conducted face-toface at the Royal Children's Hospital, Melbourne ( $\mathrm{RCH})$ and two were conducted over the phone between February- April 2019. Interviews were semi-structured, ranging from 30 minutes to 1 hour in duration. Box 1 summarises broad interview questions. Interviews were audio-recorded using GarageBand on LS's laptop and transcribed verbatim. Pseudonyms replaced participants names on recordings and transcripts.

\section{- Data processing and analysis}

This article is protected by copyright. All rights reserved. 
Data was analysed using inductive content analysis to identify emergent ideas regarding OHIS. Analytic steps involved: 1)importing transcripts into an NVivo software program; 2)reading and identifying sections of the transcript which demonstrated participants' perspectives and experiences. These were then listed as codes in NVivo. At this point a sample of the transcripts were also coded independently by coresearchers (CD and NW). Data analysis then progressed to 3)a process of iterative comparison across transcripts to identify elements emerging from data relevant to the research question. Codes were then clustered together to form broader sub-themes and themes.

During this time, monthly meetings were held with co-researchers to discuss and compare analytic findings. During meetings, the issue of reaching saturation was also discussed, and it was agreed that "sufficient data to account for all aspects of the phenomenon [had] been obtained"23p18.

\section{- Trustworthiness}

In accordance with Lincoln and Guba's ${ }^{24}$ widely accepted criteria about trustworthiness in qualitative research, 4 strategies were employed. First, prolonged engagement involved LS interviewing all participants, transcribing and studying all data from raw material. Secondly, investigator triangulation was applied by involving a team of three researchers involved in project organisation and data analysis. Meetings were held regularly between researchers to check the preliminary findings and interpretations and to ensure a consensus regarding themes was established. Thirdly, persistent observation was applied by continually re-reading, analysing and revising concepts according to meeting discussions. The final strategy was maintaining an audit trail. Records of all raw interview data, transcripts and meeting notes were kept.

\section{- Ethics}

Ethical approval was obtained from the University of Melbourne Human Research Ethics Committee(ID:1853175.1). Written informed consent was provided by all participants via a signed consent form and pseudonyms were used. 


\section{RESULTS}

\section{Participants}

13 clinicians participated in this research including; four physiotherapists (experience- 2.5- 30 years), eight paediatricians (experience- 1.5- 24 years) and one nurse consultant (experience- 15 years). All participants were actively involved in working regularly with children with $\mathrm{CP}$, as part of a multidisciplinary team. 12 participants were employed by a single large paediatric hospital in Melbourne and one was employed by a rural public health hospital.

\section{Themes}

Three broad themes were developed from data analysis. Each of these themes represent a range of statements from participating clinicians reflecting their perceptions of the effects of parental OHIS on parents (theme one), clinicians (theme two) and the clinical dynamic (theme three). Table 1 provides quotes attributed to each of these themes as examples of participant responses.

\section{The informed parent}

Participants described an outcome of OHIS to be parents entering clinical encounters with 'more information'. This was described as both a positive and negative effect.

\section{1a) Online information that informs and empowers parents}

All participants discussed how OHI could be utilised to aid parents understanding of their child's health condition. They viewed the informed parent as being 'empowered' as they were able to more actively engage and contribute to consultations.

\section{1b) Online information that emotionally and socially support parents}

Participants also discussed how online forums could provide an emotional and social support for parents as they allow parents to connect with one another, exchange knowledge and build relationships based on shared experiences.

\section{1c) Online information that misinforms or misleads parents}


Participants raised concern that OHI could mislead or misinform parents. They discussed how parents may find information online that is false, not evidence-based or 'biased' and that parents may be misled as they may lack the capacity to evaluate OHI and apply it appropriately.

\section{The clinicians' role}

A second strong message to emerge from interviews was a sense of disruption to the clinicians' role. The first subtheme relates to clinicians' positive views on the 'informed parent'. The second and third subthemes highlight how clinicians spend more time and effort managing expectations, negotiating conflicting views and juggling their roles with the 'informed' parent.

\section{2a) Positives of the pre-informed parent}

In some cases, participants believed OHIS could have positive effects. Firstly, participants discussed how OHIS could make their job 'easier' as parents entered clinical encounters with a base of information that facilitated advice they gave. A second positive effect was how OHIS could increase pressure on clinicians to be on top of information, viewing OHIS as an opportunity to keep medical knowledge up-to-date.

\section{2b) More difficult and time consuming to provide advice and manage expectations}

Parental OHIS means clinicians are no longer parents’ primary source of medical information. Participants reflected on how OHIS made it more difficult for them to give advice. They also discussed how parents bringing $\mathrm{OHI}$ also meant they spent more time discussing OHI. This additional time spent discussing $\mathrm{OHI}$ could result in other components of the consultation being sacrificed.

\section{2c) Juggling roles and duties}

Participants discussed how OHIS resulted in a greater potential for disagreements between clinicians and parents about the appropriate care for a child, as OHI may not be in accordance with available evidence or clinically indicated. They described the difficulty this caused for them in balancing their duty to act in the child's best interest whilst trying to maintain an ongoing relationship with families.

\section{A new clinical dynamic}


The changes to the role of the parent and the clinician led to the overriding theme of 'a new clinical dynamic'. The first two subthemes under theme three capture the positive effects of OHIS on this new dynamic. The negative impact of OHIS on the dynamic, captured in the third subtheme, relates to an apparent change in parents' trust in clinicians.

\section{3a) More balance and collaboration}

Participants believed OHIS was changing the clinician-parent relationship and causing a shift in the 'power balance' within interactions. They discussed how OHI saw parents take on a more collaborative role, creating a more 'balanced', 'partner-like' relationship with greater mutual understanding of therapeutic decisions.

\section{3b) A shared language}

Participants also described how OHIS could improve communication between parents and clinicians. In some cases, participants believed parents' access to OHI facilitated discussion and saw them ask more relevant, informed questions.

\section{3c) A change to trust}

Clinicians discussed how they believed parental OHIS could cause some distrust in their medical expertise. They described their experiences of online sites being used by parents to judge clinicians which could see parents developing false beliefs.

This article is protected by copyright. All rights reserved. 


\section{DISCUSSION}

This aim of this research was to explore clinicians' experiences of parental OHIS behaviour and its effects in the context of parents seeking SDR for their children with CP. Clinicians acknowledged a number of effects of OHIS on parents and clinicians which largely support that of earlier literature. Positive effects include a more informed and supported parent ${ }^{2,9,25}$, provision of more up-to-date advice and a more balanced parent-clinician relationship ${ }^{26}$. Negative effects discussed include the potential for OHIS to misguide parents ${ }^{26,12}{ }^{13}$, the additional effort required from clinicians to discuss $\mathrm{OHI}$ and manage parental expectations ${ }^{26}$, the increased possibility for conflict ${ }^{12,14}$ and responding to a sense of diminished trust from parents ${ }^{27,28}$.

The overarching finding from this research which elaborates on existing literature is the idea of a 'new clinical dynamic'. By focusing on the perspectives of paediatric clinicians, the findings add new knowledge to our understandings of how OHIS is affecting the role of clinicians and the clinician-parent communication dynamic. This is based on clinicians' perceptions of OHIS as an 'unsettling' or ‘disruptive' force. Discussions with participants highlight that clinicians are wrestling with how to best balance, on the one hand, providing care which promotes the wellbeing of a child based on clinical evidence, and on the other, respecting parents' moral authority to make decisions about what they see as best for their child ${ }^{29}$.

One important implication of these findings is a need to rethink the clinician-parent communication agenda and determine strategies for clinicians to allow discussions to be negotiated in a shared way. There is currently some research occurring in this space. For example, in the adult setting, Gerber et al. ${ }^{7}$, Bylund et al. ${ }^{30}$ and Wald et al. ${ }^{14}$ explore strategies for clinicians to integrate OHIS within clinical practice. These studies recommend a 'net-friendly' clinician who provides an 'internet prescription' whereby clinicians direct patients to credible online sources ${ }^{7,14,30}$. They suggest that if clinicians actively assist patients in the information seeking process, the clinician-patient relationship may improve ${ }^{7,14,30}$. Another suggestion derived from these studies is that clinicians provide positive reinforcement to OHIinformed patients to praise efforts to increase medical knowledge ${ }^{7,14,30}$. In the paediatric setting, and in the context of parents actively searching for cures or breakthroughs for their child living with a long-term and incurable condition, there is a need to recognise, acknowledge and integrate parental values and motivations to seek online support into routine clinical communication ${ }^{31}$. 
Based on this current research and the emerging literature on OHIS and clinical practice, there is a need for education to focus on redefining the clinicians' role and guidance for clinicians on how to ethically evaluate situations where parents are pursuing treatments which may not be in the best interests of the child but are available in the private sector. In the specialty area of paediatrics, clinicians are required to not only respect parents' views and facilitate shared decision-making, but also to separately analyse whether and how the requested treatment is in a child's best interests. The idea of the 'zone of parental discretion' (ZPD) suggests that although parents have moral authority to make health decisions in the interests of their child, their autonomy is not limitless and is restricted if their decisions are likely to cause significant harm to their child ${ }^{29}$. For clinicians, the ZPD provides a systematic way to think through situations of disagreement between clinicians and parents by focusing attention on the moral weight of parents as the decision-makers for the child in addition to focusing on the wellbeing of the child ${ }^{29}$. Using the ZPD encourages a focus on the concrete outcomes of parents' and clinicians’ perspectives. It assists clinicians to distinguish between their bottom line response of when to override and when to allow the parents' requests, even though they consider them to be medically suboptimal ${ }^{29}$. In the context of children with CP, paediatric clinicians must weigh up whether parents' requests for specific treatment for their child, based on their OHIS, falls within the ZPD 29.

This study also highlights opportunities for future research. A key finding of the research is that clinicians' experienced OHIS as an 'unsettling' or 'disruptive' force. Research has identified that OHIS is already transforming relationships between health professionals and their clients ${ }^{32}$. In the paediatric context, further research is needed to determine how clinicians are managing this changing dynamic and to determine what education and support they require to adjust and integrate this new dynamic into their models of communication and goals of care. Further empirical questions to be explored include: How often do clinicians do online searching with the families? How does parental OHIS activity impact on clinicians' sense of themselves as a professional with expert knowledge?

This study was on a small scale, with the majority of clinicians from one centre and a focus on one paediatric condition. Future studies could extend this research across a broader number of centres and consider parental OHIS in the context of different illnesses. This may provide greater insight as well as a greater ability to generalise findings.

\section{Limitations and generalisability}


Limitations of the study relate to the small sample and single clinical area studied which limits its generalisability. Experiences explored in this study may not necessarily be representative of all paediatric clinicians or conditions. As a qualitative study, this project was also heavily dependent on the primary researcher and was therefore open to researcher bias. In addition, experiences reported by participants were retrospective across a broad time period of past experiences which may be viewed as a potential source for recollection bias ${ }^{33}$.

Although limiting the generalisability of the findings, the qualitative approach is highly suitable to enable participants to provide their subjective experience of parental OHIS. Attention to trustworthiness was addressed throughout and the findings provide rich and contextual information which allows the reader to make sense of the data and determine its applicability to their own clinical or academic work. The consistency of the themes with past research suggests the findings may have broader relevance for clinicians in other areas of practice. Greater participant numbers across a broader range of sites would provide a richer data set and improve generalisability.

This article is protected by copyright. All rights reserved. 


\section{CONCLUSION}

This research shows OHIS is changing the role of the parent, clinician and overall dynamic of the clinical encounter. Armed with OHI, parents may lead clinical discussions with their requests and some clinicians report they are responding by explaining and justifying, rather than 'controlling' the treatment agenda.

The research shows that clinicians are uncertain and, at times, struggling to adjust to this new dynamic. It suggests a need for support to aid clinicians in their adjustment to the 'informed' parent.

With increasing numbers of users accessing health information online, OHIS will continue to play a role in paediatrics. It is hoped that the findings from this study will raise awareness and highlight areas for future research to better address clinicians needs in the ever-growing presence of parental OHIS.

This article is protected by copyright. All rights reserved. 


\section{REFERENCES}

1. Fox S. Online health search 2006. [Internet]. Washington DC: Pew Internet \& American Life Project; 2006 Oct 29. [cited 2019 Feb]. Available from: https://www.pewinternet.org/wpcontent/uploads/sites/9/media/Files/Reports/2006/PIP_Online_Health_2006.pdf.pdf

2. Canty MJ, Breitbart S, Siegel L, Fehlings D, Milo-Manson G, Alotaibi NM, et al. The role of social media in selective dorsal rhizotomy for children: Information sharing and social support. Childs Nerv Syst. 2019;11;1-7. DOI: 10.1007/s00381-019-04197-x

3. St-Laurent-Gagnon T, Coughlin KW, Canadian Paediatric Society BC. Paediatricians, social media and blogs: Ethical considerations. Paediatrics \& Child Health. 2012;17(5);267-72. Available from: https://www.ncbi.nlm.nih.gov/pmc/articles/PMC3381922/\#_ffn_sectitle

4. Khoo K, Bolt P, Babl FE, Jury S, Goldman RD. Health information seeking by parents in the Internet age. J Paediatr Child Health. 2008;44(7-8);419-23. DOI: https://dx.doi.org/10.1111/j.14401754.2008.01322.x

5. Gage EA, Panagakis C. The devil you know: Parents seeking information online for paediatric cancer. Sociology of Health \& Illness. 2012;34(3);444-58. DOI: 10.1111/j.1467-9566.2011.01386.x 6. Bernhardt JM, Felter EM. Online pediatric information seeking among mothers of young children: Results from a qualitative study using focus groups. J Med Internet Res. 2004;6(1);e7. DOI: 10.2196/jmir.6.1.e7

7. Gerber BS, Eiser AR. The patient physician relationship in the Internet age: Future prospects and the research agenda. Journal of Medical Internet Research. 2001;3(2);E15. DOI: 10.2196/jmir.3.2.e15 8. Blackburn C, Read J. Using the Internet? The experiences of parents of disabled children. Child: Care, Health and Development. 2005;31(5);507-15. DOI: 10.1111/j.1365-2214.2005.00541.x 9. Hall JG. The role of patient advocacy/parent support groups. South African Medical Journal SuidAfrikaanse Tydskrif Vir Geneeskunde. 2013;103(12 Suppl 1);1020-2. DOI: 10.7196/samj.6976

10. Semere W, Karamanoukian HL, Levitt M, Edwards T, Murero M, D'Ancona G, et al. A pediatric surgery study: Parent usage of the Internet for medical information. Journal of pediatric surgery. 2003;38(4);560-4. DOI: 10.1053/jpsu.2003.50122

11. Holland ML, Fagnano M. Appropriate antibiotic use for acute otitis media: What consumers find using Web searches. Clinical Pediatrics. 2008;47(5);452-6. DOI: 10.1177/0009922807313274 12. Tan SS, Goonawardene N. Internet health information seeking and the patient-physician relationship: A systematic review. Journal of Medical Internet Research. 2017;19(1);e9. DOI: 10.2196/jmir.5729

13. Impicciatore P, Pandolfini C, Casella N, Bonati M. Reliability of health information for the public on the world wide web: Systematic survey of advice on managing fever in children at home. BMJ. 1997;314(7098);1875. DOI: 10.1136/bmj.314.7098.1875

14. Wald HS, Dube CE, Anthony DC. Untangling the Web: The impact of Internet use on health care and the physician-patient relationship. Patient Education and Counseling. 2007;68(3);218-24. DOI: 10.1016/j.pec.2007.05.016

15. Oliveira JFd. The effect of the internet on the patient-doctor relationship in a hospital in the city of São Paulo. Journal of Information Systems and Technology Management. 2014;11;327-44. DOI: http://dx.doi.org/10.4301/S1807-17752014000200006

16. Grunt S, Fieggen AG, Vermeulen RJ, Becher JG, Langerak NG. Selection criteria for selective dorsal rhizotomy in children with spastic cerebral palsy: A systematic review of the literature. Developmental Medicine \& Child Neurology. 2014;56(4);302-12. DOI: 10.1111/dmcn.12277

17. Anonymous. The definition and classification of cerebral palsy. Developmental Medicine \& Child Neurology.49(s109);1-44. DOI: https://doi.org/10.1111/j.1469-8749.2007.00001.x 
18. Attfield SJ, Adams A, Blandford A. Patient information needs: Pre- and post-consultation. Health Inform J. 2006;12(2);165-77. DOI: 10.1177/1460458206063811

19. O'Brien BC HI, Beckman TJ, Reed DA, Cook DA. Standards for reporting qualitative research: a synthesis of recommendations. Acad Med. 2014;89(9);1245-51. DOI: 10.1097/ACM.0000000000000388.

20. Starks H, Brown Trinidad S. Choose your method: A comparison of phenomenology, discourse analysis, and grounded theory. Qual Health Res. 2007;17(10);1372-80. DOI:

$10.1177 / 1049732307307031$

21. Groenewald T. A phenomenological research design illustrated. International Journal of Qualitative Methods. 2004;3(1);42-55. DOI: 10.1177/160940690400300104

22. Liamputtong P. Qualitative research methods. 4th ed. Melbourne: Oxford University Press; 2013.

23. Morse JM, Barrett M, Mayan M, Olson K, Spiers J. Verification strategies for establishing

reliability and validity in qualitative research. International Journal of Qualitative Methods. 2002;1(2);1322. DOI: $10.1177 / 160940690200100202$

24. Nowell LS, Norris JM, White DE, Moules NJ. Thematic snalysis: Striving to meet the trustworthiness criteria. International Journal of Qualitative Methods. 2017;16(1);1609406917733847. DOI: $10.1177 / 1609406917733847$

25. Nicholl H, Tracey C, Begley T, King C, Lynch AM. Internet use by parents of children with rare conditions: Findings from a study on parents' Web information needs. Journal of Medical Internet Research. 2017;19(2);e51. DOI: 10.2196/jmir.5834

26. Chrismann S. The impact of online health information on the doctor-patient relationship. Findings from a qualitative study. London School of Economics and Political Science. 2013. Available from: http://www.lse.ac.uk/media@lse/research/mediaWorkingPapers/MScDissertationSeries/2012/78.pdf 27. Daskivich TJ, Houman J, Fuller G, Black JT, Kim HL, Spiegel B. Online physician ratings fail to predict actual performance on measures of quality, value, and peer review. Journal of the American Medical Informatics Association. 2017;25(4);401-7. DOI: 10.1093/jamia/ocx083

28. Haskins IN, Krpata DM, Rosen MJ, Perez AJ, Tastaldi L, Butler RS, et al. Online surgeon ratings and outcomes in hernia surgery: An Americas Hernia Society quality collaborative analysis. Journal of the American College of Surgeons. 2017;225(5);582-9. DOI: 10.1016/j.jamcollsurg.2017.08.007

29. McDougall R, Delany C, Gillam L. When doctors and parents disagree: Ethics, paediatrics and the zone of parental discretion. Sydney, NSW: The Federation Press; 2016.

30. Bylund CL, Gueguen JA, Sabee CM, Imes RS, Li Y, Sanford AA. Provider-patient dialogue about Internet health information: An exploration of strategies to improve the provider-patient relationship.

Patient Educ Couns. 2007;66(3);346-52. DOI: 10.1016/j.pec.2007.01.009

31. Morrow AM, Quine S, Loughlin EV, Craig JC. Different priorities: A comparison of parents' and health professionals' perceptions of quality of life in quadriplegic cerebral palsy. Archives of Disease in Childhood. 2008;93(2);119-25. DOI: 10.1136/adc.2006.115055

32. Hardey M. Doctor in the house: The Internet as a source of lay health knowledge and the challenge to expertise. Sociology of Health \& Illness. 1999;21(6);820-35. DOI: 10.1111/14679566.00185

33. Kornhaber R, Wilson A, Abu-Qamar MZ, McLean L. Coming to terms with it all: Adult burn survivors' 'lived experience' of acknowledgement and acceptance during rehabilitation. Burns : Journal of the International Society for Burn Injuries. 2014;40(4);589-97. DOI: 10.1016/j.burns.2013.08.038 


\section{APPENDIX}

Box 1: Interview questions

\section{Question}

1 Have you had clinical encounters with parents who are informed about aspects of their children's health and management options from OHIS?

How often is this occurring?

3 How do you generally respond to these sorts of encounters?

$4 \quad$ How would you describe your role in these situations?

$5 \quad$ Do you find anything challenging or concerning?

$6 \quad$ Have you encountered requests from parents for the specific treatment of SDR for their child?

$7 \quad$ In general how has OHIS influenced parents understanding of CP and SDR?

This article is protected by copyright. All rights reserved. 
Table 1: Themes/subthemes and representative quotes from participants

\section{Main themes}

The informed

parent

parents

\section{Representative quotes}

The parent comes in as an expert, and that's partly because of what they've read online. (P12)

I mean on one hand I think it is quite empowering for the parents that they have things they can read and get up to date with what the literature is. (P2)

Online information and And they can also talk to other parents who are going through forums that emotionally the same thing, which I think can be helpful and valuable. and socially support Sometimes it isn't, but sometimes it is important to get support parents from other people with children with CP or spasticity and their experiences and that can be a really nice support network because I can imagine you can feel quite isolated. So it's like a social form of support and emotional support. (P6)

Online information that The stuff on social media is all sort of the happy, success stories misinforms or misleads and that's what parents are seeing...So it's a very biased parents perspective... (P6)

Well I guess people can't work out whether the info is relevant or not to their child. (P9) 
The clinicians' Positives of the pre-

role

informed parent ...it helps. They don't just come in and you say, 'ok well we want to do this surgery an SDR' and they are like 'oh I've never even heard about that'. That doesn't happen they are always like 'yeh, yeh I know about that'. (P6)

I think it has just making sure, made me more on top of my game. (P2)

More difficult and time They come in with a decision about wanting a treatment, even consuming to provide though that might not be the best decision for them or the right advice and manage treatment for their child, and they come in pretty adamant that expectations they want it because of what they've read or seen online. (P6)

Yeh, you could be sacrificing the entire consultation just to address the patients concerns. And, you know, you may not progress in the current treatment...(P10)

Yeh I think if its information that they have read that they are really advocating for or that they are really I guess, believing in it and it's not something that I would recommend based on my own knowledge and research then yeh, definitively puts forward a conflict $(\mathrm{P} 1)$

This article is protected by copyright. All rights reserved. 
So, it's, your ego is affected. Your status as a clinician is affected, you do sometimes wonder well what is my role here? It can be frustrating (P12)

A new clinical More balance and dynamic
It's shifted the, you know, like the power balance in the relationship a bit perhaps. Towards being more balanced, more collaborative... (P3)

...And I think, you know that the good old days when the doctor was the you know the be all and end all and what the doctor said you did, is well and truly gone. (P3)

So, I think the reading is helpful because parents who come with things sometimes have started to formulate questions, so they have better or more relevant questions they want to ask...(P8)

A change to trust

What can happen is that they can find information online, you can feel like you're the, a sort of trusted information as a professional, a health professional. They can come and ask you and you can give them information...and then they can basically say well they don't believe you. (P7)

This article is protected by copyright. All rights reserved. 


\section{Paediatric clinician's experiences of parental online health information seeking: a qualitative study}

Type of manuscript: Original Article

Authors: Lily Shervington ${ }^{1}$, Dr Neil Wimalasundera ${ }^{2}$, Professor Clare Delany ${ }^{1}$

Institution: The Royal Children’s Hospital Melbourne

50 Flemington Rd, Parkville VIC 3052

Correspondence to: Lily Shervington ${ }^{1}$

2/30 Napoleon St., Collingwood, VIC 3066

Lilyshervington93@gmail.com

(61)434980936

${ }^{1}$ The Department of Paediatrics, University of Melbourne, Australia

${ }^{2}$ Royal Children’s Hospital, Melbourne, Australia

\section{Acknowledgements}

The authors would like to thank the participants of the project for giving up their time to contribute their experiences and expertise.

\section{Conflicts of interest}

None declared

\section{Contributors}

All three authors contributed to the design, analysis and writing in this paper. LS collected the data and all three authors contributed to the analysis and writing.

\section{Funding}

This research received no specific grant from any funding agency in the public, commercial or not-for-profit sectors

This article is protected by copyright. All rights reserved. 


\section{University Library}

\section{- M M N E R VA A gateway to Melbourne's research publications}

Minerva Access is the Institutional Repository of The University of Melbourne

Author/s:

Shervington, L;Wimalasundera, N;Delany, C

Title:

Paediatric clinician's experiences of parental online health information seeking: A qualitative study

Date:

2019-12-17

Citation:

Shervington, L., Wimalasundera, N. \& Delany, C. (2019). Paediatric clinician's experiences of parental online health information seeking: A qualitative study. JOURNAL OF

PAEDIATRICS AND CHILD HEALTH, 56 (5), pp.710-715. https://doi.org/10.1111/jpc.14706.

Persistent Link:

http://hdl.handle.net/11343/286756 